\title{
The Place of e-learning in ALS Teaching
}

\section{Małgorzata Grześkowiak ${ }^{1}$, Piotr Rzeźniczek ${ }^{1}$, Adam Pytliński $^{1}$, Jacek Stańdo ${ }^{2}$, Magdalena Roszak ${ }^{3}$}

${ }^{1}$ Department of Teaching Anesthesiology and Intensive Therapy, Poznan University of Medical Sciences, Poland

2 Centre of Mathematics and Physics, Lodz University of Technology, Poland

3 Department of Computer Science and Statistics, Poznan University of Medical Sciences, Poland

\begin{abstract}
This paper presents the place of e-learning methods in the teaching of Advanced Life Support (ALS) to second year medical students. The described course lasts 30 hours and consists of lectures, seminars, and classes. Numerous modifications of the course were introduced in the past and at the moment electronic learning methods are being improved with new ones being added as well. The following have been implemented: 1. e-learning presentations instead of lectures; 2 . recording own instructional movie demonstrating advanced cardiopulmonary resuscitation; 3 . a change in the method of conducting practical classes consisting in recording the medical procedures performed by students with a camera. Although e-learning plays an important role in ALS teaching, it cannot completely replace on-site classes. Thus, ALS without any practice to acquire resuscitation skills is impossible.
\end{abstract}

\section{Introduction}

Advanced Life Support (ALS) is a procedure of high-level treatment dedicated to patients in life-threatening conditions, especially those in cardiac arrest and needing cardio-pulmonary resuscitation. The ALS recommendations used in Poland are the guidelines of the European Resuscitation Council, which are updated every 5 years. Due to the Covid-19 pandemic, the current guidelines were published in 2021 (Soar et al., 2021).

ALS guidelines are included as part of the syllabus at the second year of study at Poznan University of Medical Sciences for Polish as well as for English-speaking medical students. The current course lasts 30 hours and consists of lectures, seminars, and classes. Recently, numerous modifications have been made to it. The idea is to provide students with a modern product 
that can be used at home at any time with treatment techniques presented electronically that have so far been unavailable in this form.

Modifications that make use of multimedia (cameras) were introduced at the department for the first time in 2018. The next step was to prepare e-learning presentations for students, which were of great help during the Covid-19 pandemic when distance learning was the method of choice (Grześkowiak et al., 2020). At the moment, electronic learning methods are still being improved and certain new ones are being added as well (Figure 1).

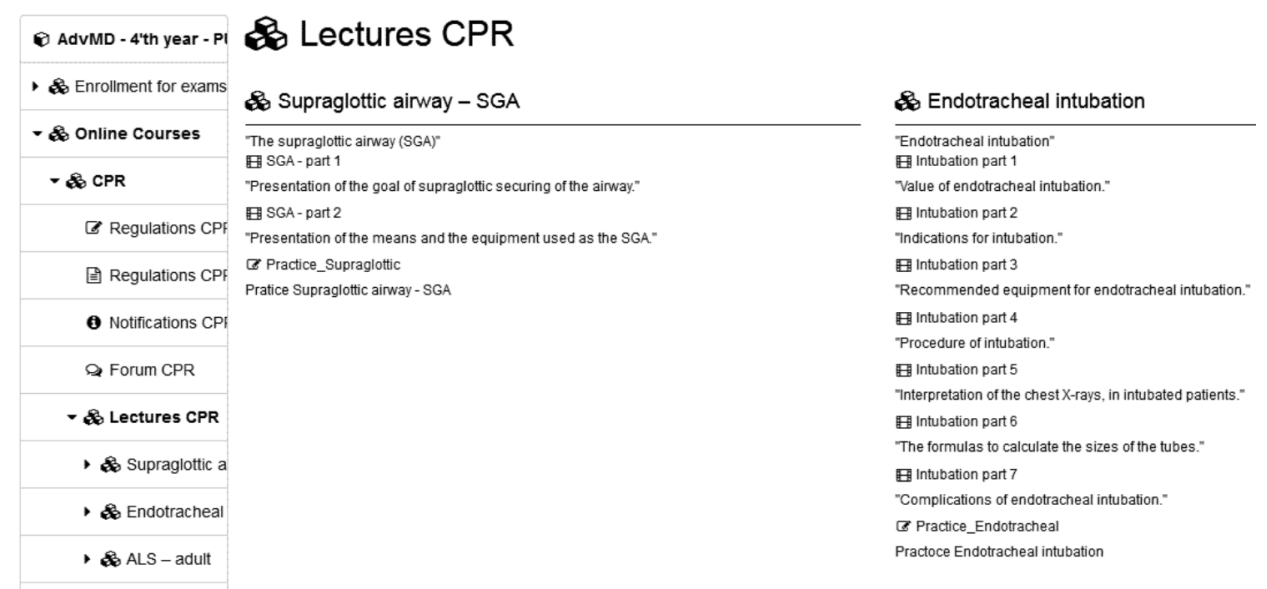

Figure 1. The lectures available for students by e-learning (SGA and intubation)

\section{The Plan of the Implemented Changes}

1. First, the lectures (6 hours) were changed from traditional to elearning. The idea of e-learning was to present the most important issues included in the ALS recommendations to the students and explain in detail how different methods of treatment work, presenting as much content as possible by means of pictures, diagrams, and photographs (Figure 2).

2. Moreover, the idea was to prepare an own movie devoted to advanced cardiopulmonary resuscitation, to be made available to students as an elearning tool. The authors were the actors playing the roles of rescuers. While shooting the movie, it was possible to demonstrate all the steps of treatment, add comments, and edit the movie in such a way as to highlight the important moments and explain them by including subtitles (Figure 3, 4). 


\begin{tabular}{|c|c|c|}
\hline - 8 PALS & $\$$ ALS - adult & $\$$ PALS \\
\hline ALS - movie & $\begin{array}{l}\text { "Advanced Life Support - ALS Adult" } \\
\text { B ALS - adult part } 1\end{array}$ & $\begin{array}{l}\text { "Pediatric Advanced Life Support PALS" } \\
\text { PALS part } 1\end{array}$ \\
\hline G Folder CPR & "Presentation of the ALS algorithm for adults." & "Intro." \\
\hline$b$ Folder CPR & BALS-adult part 2 & $\mathbb{E P A L S}$ part 2 \\
\hline$\square$ Question to Tea: & "Presentation of the important recommendations entered into the procedure of resuscitation." & "Following steps of advanced resuscitation. Drugs and preparation." \\
\hline Epidemiology & "Drugs administered during resuscitation." & "Algorithm of the PALS." \\
\hline & B ALS - adult part 4 & G Pratice_PALS \\
\hline - 8 immunology & "Presentation of the technique of defibrillation." & Pratice_PALS \\
\hline - \& Pathophysiology & The reversible causes of cardiac arrest- $4 \mathrm{Hs}, 4 \mathrm{Ts}(5 \mathrm{Hs}, 5 \mathrm{Ts})$." & \\
\hline - Pathology II & $\begin{array}{l}\text { Co Practice_ALS Adult } \\
\text { Practice_ALS Aduit }\end{array}$ & \\
\hline
\end{tabular}

Figure 2. Lectures available to students as e-learning materials (ALS-adult, PALS = pediatric ALS)

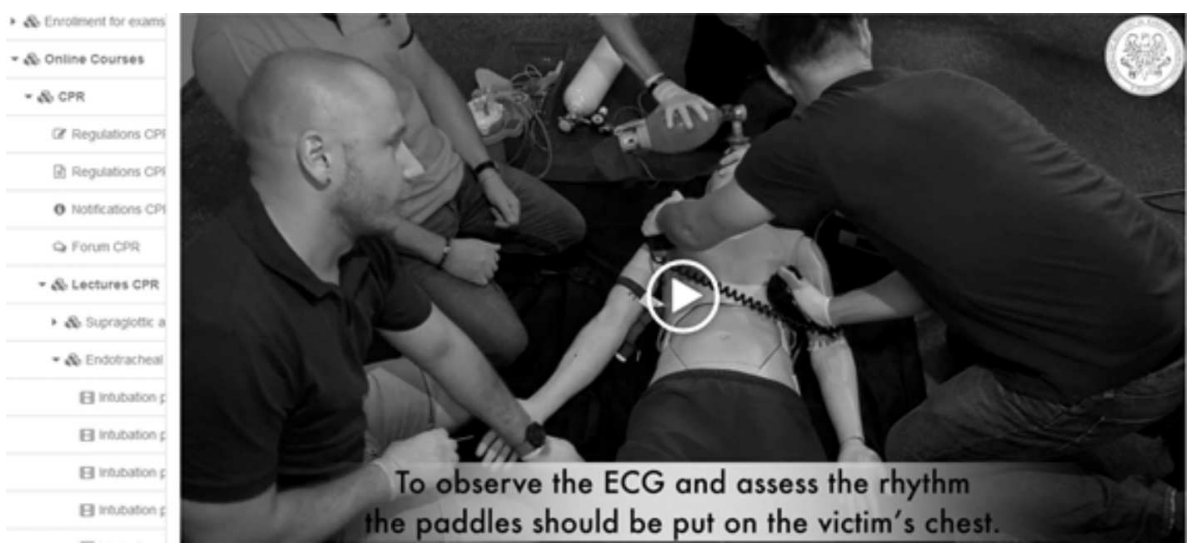

Figure 3. The written comments used in the ALS movie during freeze-frame

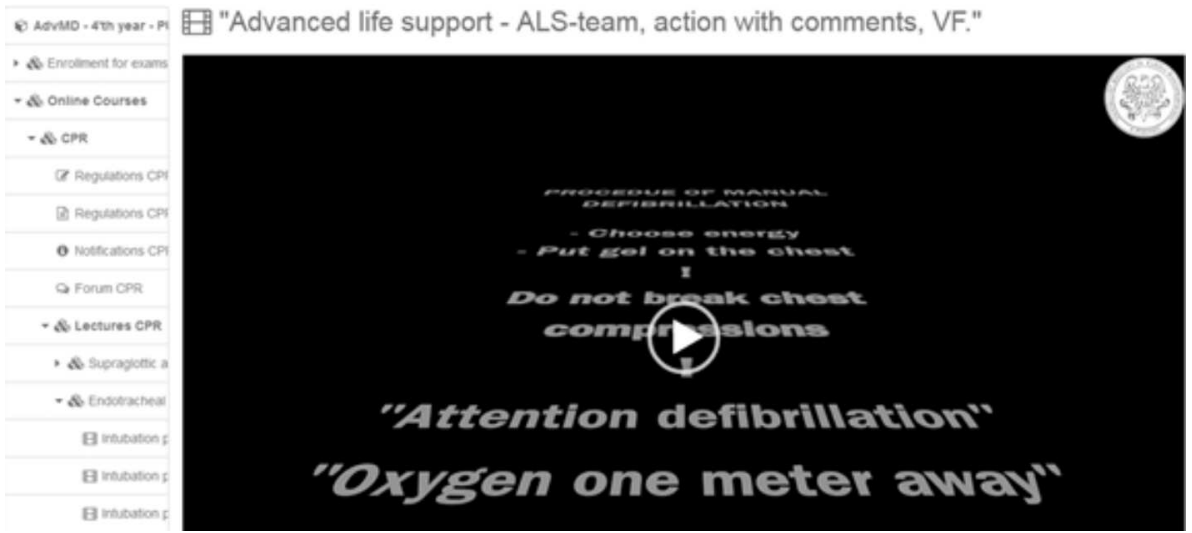

Figure 4. The procedure of defibrillation as text used in the ALS movie - the text layout is the same as in the "Star Wars" movie (it was prepared in this way on purpose so that the students would remember the procedure of defibrillation better) 
Małgorzata Grześkowiak et al.

The authors produced scenes focused on the treatment of different rhythms present in cardiac arrest, such as ventricular fibrillation or pulseless ventricular tachycardia. First, the students were offered a scene presenting a resuscitation procedure recorded in real time during the treatment of a patient. Then the same scene was prepared in the following a way: the scene was frozen to add a comment to emphasize an important moment (Figure 5,6).

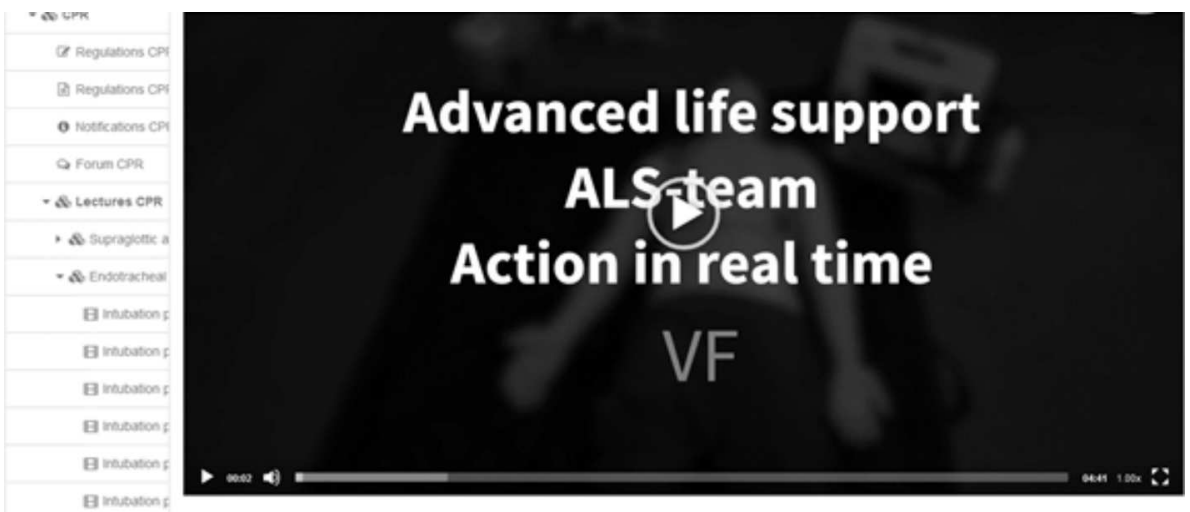

Figure 5. ALS movie in real time

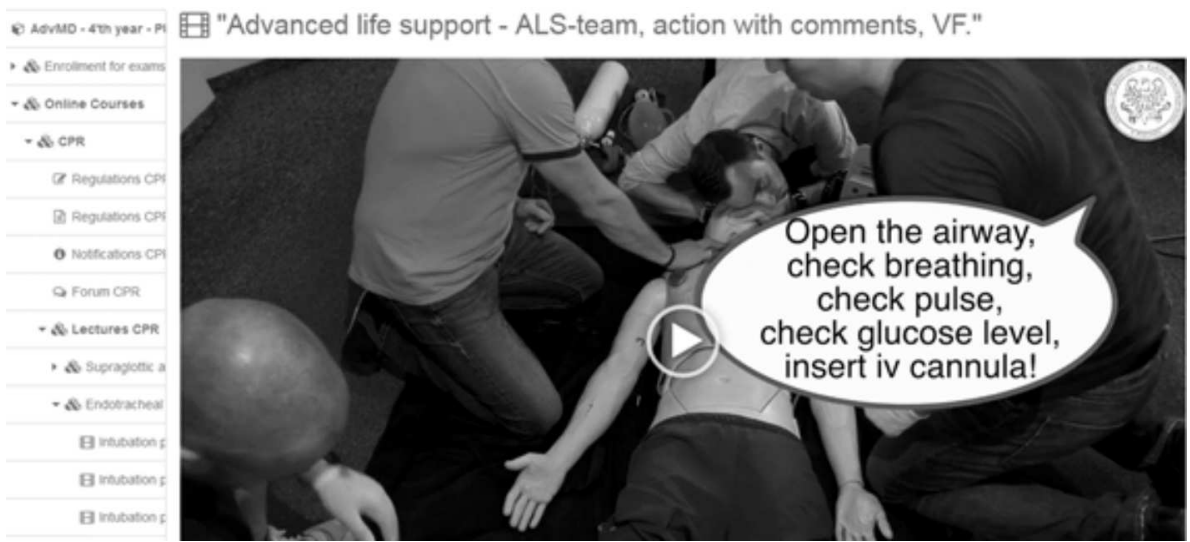

Figure 6. Written comments used in the ALS movie during freeze-frame

3. The method of conducting practical classes during which students practice the procedures was changed. Once the students had acquired the skills necessary to work in a resuscitating team, they were asked to perform resuscitation again, but this time the procedure was recorded 
with a camera. As students completed the treatment of a patient according to a pre-prepared scenario, the camera was turned off. Afterwards, the students were asked to watch the movie, which constituted a kind of feedback.

\section{Face-to-face Classes}

During on-site classes, many of the electronic methods of learning prepared earlier were used. First of all, students' knowledge acquired from the e-learning presentations was checked each day before the beginning of faceto-face classes. Then, e-learning presentations and the instructional video were used to introduce the students to the subject matter of the classes. Additionally, a video camera with a state-of-the-art adult phantom were used. For the purpose of employing the multimedia elements during faceto-face classes, 2 out of the 5 planned days were devoted to the implementation of the subject by each group of students. The element of simulation was introduced on the $3^{\text {rd }}$ day of classes, after the students had become acquainted with the technique of performing activities in medical teams and had been given a content-related introduction to the classes. On the $1^{\text {st }}$ day of the simulation, the students formed 4-person medical teams. All the people participating in the simulation were assigned to perform a medical rescue procedure. The activities were carried out on a phantom simulating an adult patient, with the use of the available medical equipment. The students were presented 2 medical cases related to lifethreatening conditions. After the case presentation was completed, the students began to simulate advanced life support and had to perform all activities on their own. During the classes, the multimedia element consisted in the use of a video camera that recorded the activities performed by students. The video recording of medical activities began with the reading of the case of the simulated patient, with the end of the recording signalled by the teacher. On the first day of the simulation, the main goal was to activate students to carry out independent rescue operations, without the participation and supervision of teachers. A video recording of the students' activities was needed to reproduce them on the second day of the seminar in order to analyse the tasks performed. This simulation stage was aimed at activating the students to detect their own mistakes while being presented the recreated medical cases. For this reason, the supervisor did not interrupt the team's activities during the recording of the medical procedures. 


\section{What Cannot Be Replaced by e-learning}

It is obvious that skills such as ventilation of the patient, securing the airway by introducing the supraglottic airway (SGA) or by endotracheal intubation, defibrillation, and intravenous or intraosseous access should be practiced and it is impossible to acquire them without training. Similar skills were practiced on-site during the pandemic (Gintrowicz et al., 2021). Hence, in the discussed course, e-learning presentations were prepared whose aim was to introduce the students to the techniques involved in each of the procedures (Figure 7, 8, 9).

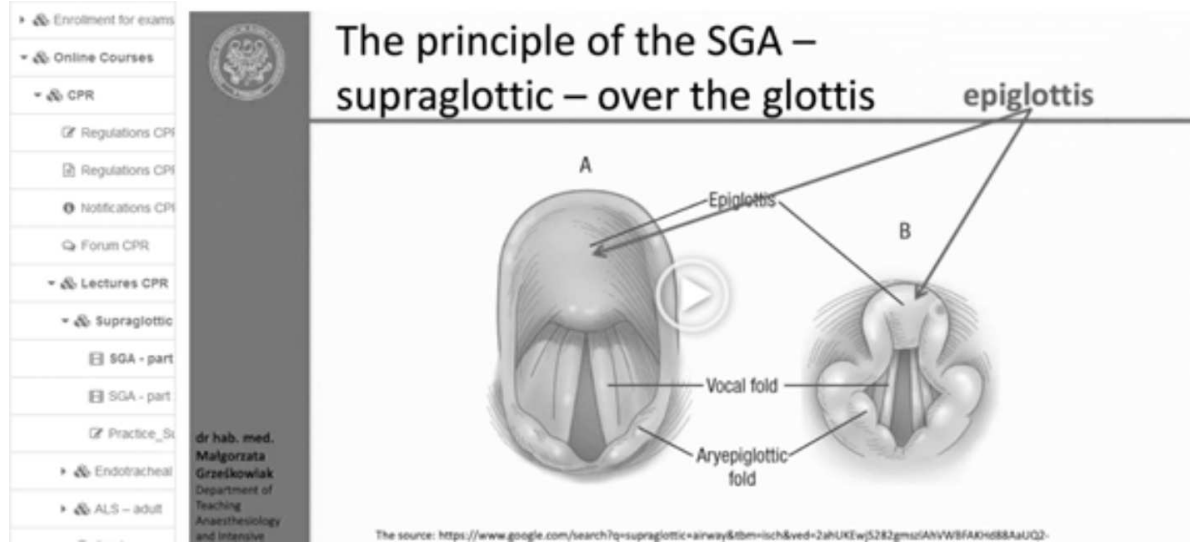

Figure 7. The use of pictures/figures in an e-learning presentation to demonstrate the principle of supraglottic airway - SGA

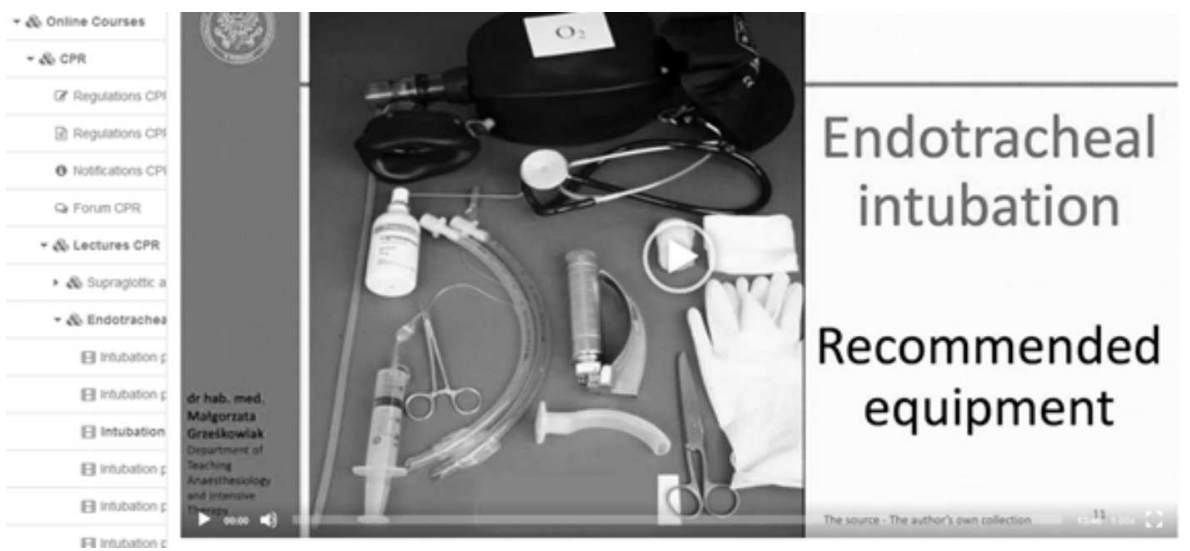

Figure 8. The use of pictures/figures in an e-learning presentation to demonstrate the recommended equipment for endotracheal intubation 


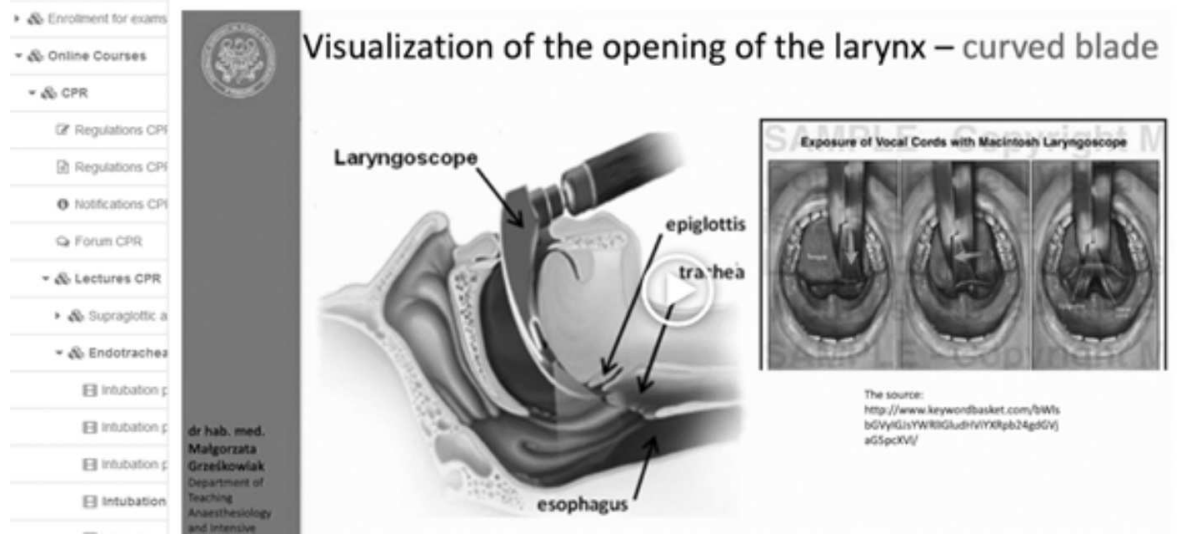

Figure 9. The use of pictures/figures in an e-learning presentation to demonstrate the technique of laryngoscopy during endotracheal intubation

The next step in the teaching process was a face-to-face meeting during which students could practice what they had learned.

In the authors' opinion, it is important to emphasize that certain elements of the ALS procedure should be practiced on-site and cannot be replaced by e-learning. Other important factors to be considered are soft learning outcomes such as teamwork and communication between the members of a team, among others.

\section{Psychological Bases of Distance Learning}

Remote education, i.e. teaching methods carried out at a distance using modern IT methods, is based on the constructivist (cognitive) concept. According to it, the human brain is treated as a set of neural units that connect with each other to form networks. It becomes a base in which information is received, stored, and processed. In terms of the cognitive concept of man, constructivism tends to treat the recipient (student) as an active subject who has an extensive pre-existing knowledge, i.e. a certain set of information and experiences that they have acquired earlier in the process of education (institutional, e.g. at school), and knowledge that they have acquired through experience (observation) of phenomena and processes in an involuntary manner (this knowledge constitutes the basis, or rather a discontinuous collection of random information). In the context of the concept of constructivism, the psychological goal of distance learning is to activate this "foreknowledge", i.e. bring it to the conscious level available to the stu- 
dent. Obviously, the degree to which this pre-existing knowledge is used depends on the student's involvement and commitment (Buss, 2001; Kozielecki, 2000; Maruszewski, 2002).

\section{Conclusions}

The place of e-learning in ALS teaching is well-established. It plays an important role in introducing students to the subject of the course in addition to describing and presenting technical aspects of medical rescue procedures. On the other hand, teaching ALS based only on e-learning without any practice to acquire resuscitation skills is impossible. Therefore, the authors suggest, similarly to others, to combine electronic learning with face-to-face practical classes (Lockey et al., 2015; O'Leary et al., 2010).

\section{R E F E R E N C E S}

Buss, D. M. (2001). Psychologia ewolucyjna. Gdańsk: Gdańskie Wydawnictwo Psychologiczne.

Gintrowicz, R., Pawloy, K., \& Degel A. (2021). Social distancing in advanced emergency medicine courses - can it work? GMS J Med Educ. 38(1), doc22. doi: 10.3205/zma001418.

Grześkowiak, M., Chudzicka-Strugała, I., Zwoździak, B., Swora-Cwynar, E., Nijakowski, K., Jokiel, M., \& Roszak, M. (2020). E-learning during the Coronavirus pandemic - creating educational resources for teaching medical students. Studies in Logic, Grammar and Rhetoric, 64(77), 77-97.

Kozielecki, J. (2000). Koncepcje psychologiczne czlowieka. Warszawa: Wydawnictwo akademickie Żak.

Lockey, A. S., Dyal, L., Kimani, P. K., Lam, J., Bullock, I., Buck, D., Davies, R. P., \& Perkins, G. D. (2015). Electronic learning in advanced resuscitation training: The perspective of the candidate. Resuscitation, 97, 48-54. doi: 10.1016/j.resuscitation.2015.09.391.

Maruszewski, T. (2002). Psychologia poznania. Gdańsk: Gdańskie Wydawnictwo Psychologiczne.

O'Leary, F. M., \& Janson, P. (2010). Can e-learning improve medical students' knowledge and competence in paediatric cardiopulmonary resuscitation? A prospective before and after study. Emerg Med Australas, 22(4), 324-329.

Soar, J., Böttiger, B. W., Carli, P., Couper, K., Deakin, C. D., Djärv, T., Lott, C., Olasveengen, T., et al. (2021). European Resuscitation Council Guidelines 2021: Adult advanced life support. Resuscitation, 161, 115-151. 